\title{
Conducting Your First AP-LS Conference Presentation: Improving the Experience for Yourself and Your Audience
}

\author{
John F. Edens \\ Southern Methodist University
}

\author{
Laura S. Guy \\ Simon Fraser University
}

You walk to the podium. You are about to give your first presentation at AP-LS. You prepared to talk for 15 minutes but the "big name" before you went 5 minutes over his time because he had "just this one last point I simply must make." You are nervous, as you've only practiced in front of the mirror and your classmates. You also realize you have 50 slides and you try not to divide that number by the 10 minutes you now have. As you open your mouth to talk, John Monahan walks in the room. You reach for a glass of water, but find that "big name" also finished the water after his presentation. Mouth dry, you realize you can barely remember the name of your major professor, let alone the subject of your talk. You take a deep breath, deciding that the audience first needs to understand your methodology in detail...

Later that night at the bar you tell your friends you think you did horribly. They say “you did fine” but don’t make direct eye contact with you when they say it...

As the recent AP-LS conference in La Jolla wrapped up, several attendees found themselves having the usual endof-conference discussion regarding the quality of the presentations. The consensus, as is characteristic most years, was that the overall quality was very good but that there were a number of recurrent problems demonstrated - mostly, although by no means exclusively, by relatively novice presenters. This led to the typical iteration of what foibles were most detrimental to doing a quality talk. Unlike previous years, however, someone suggested that it might be useful to actually provide some pre-emptive feedback to those who will present at AP-LS (or any other academic conference) in the future. Hence this column. Our goal is to try and provide some constructive suggestions in the preparation and delivery of an academic presentation, particularly when the amount of time available is brief.

\section{Preparing your Talk:}

'I'm sure they'll want to look at the fourth footnote at the bottom of the third column of my 19th slide' (or how Power Point can ruin your talk)

Power Point slides are often the source of significant audi-

\author{
John Petrila \\ University of South Florida
}

\section{Barry Rosenfeld Fordham University}

ence frustration. There are several things worth remembering about them as you prepare your talk.

- Do not put too much information on an overhead or slide. The rule of thumb that experienced conference presenters recommend is between 6 and 8 lines of text - and THIS INCLUDES DATA slides. We have all sat through presentations where the audience is asked to look at a vast matrix of data using a font size of 8 . It asks too much and the point you are trying to make will get lost. If you must make a point from an overcrowded overhead, use a pointer and be very clear what you are showing the audience. Simply pointing with your finger will not do the job.

- Related to the preceding point, do not use tables that have the equivalent font size to something you'd see in a journal. If it's so small that no one can see it and you have to explain everything, you may as well not have put it up anyway. Hit the highlights, in LARGE FONT. In general, don't use a font size less than 20 and if possible, stick with font sizes between 24 and 32 ,

- A conference presentation is not a thesis defense. Do not bring 50 slides to a 15-minute presentation. It's just not possible to cover that much material, no matter how quickly you talk. And no one will be able to follow you even if you can speak that quickly. Life is short, and so is the time you have for your presentation. Sometimes less is better, far, far better. Another good rule-of-thumb is to have one slide for every minute of presentation time - and NEVER plan to go through more than 2 slides per minute unless you are an exceptional presenter who can really fly.

- Do not show a slide, say you aren't going to cover it, and then spend 5 minutes on the slide you just said you were going to skip.

'I just spent 5 months and many, many all-nighters collecting, analyzing, and writing all about my data, submitting my proposal to AP-LS...after all that, I don't need to actually practice my talk too, do I?'

Analogous to the three most important words in real estate being 'location, location, location,' the key to a successful presentation is 'rehearsal, rehearsal, rehearsal.' Practice your talk ahead of time, preferably with an audience. Exposure 
to and repetition of your own material is the key to controlling your anxiety level and being comfortable and flexible enough to deal with any curveballs that might get thrown at you. It might also convince you that you just can't get through 50 slides in 15 minutes.

- Although perhaps over the top, one very helpful method borrowed from clinical training is to film yourself giving your talk. It's surprising what habits you are likely to notice when you watch the film- who knew your fingers could run through your hair so often and that you could say 'ummmm' every 3rd word.

- If you are presenting your thesis or dissertation, do not assume you are exempted from the above pleas to practice simply because you (should) know the information inside and out. It's amazing what gaping holes in the hippocampus can appear magically when you're speaking in front of Dr. Biggest Name Ever in your area.

- Although we are big believers in practice and preparation, too much rumination does have a downside. Do not spend too much time trying to dream up every possible question that the most methodologically and statistically savvy audience member could think up regarding your multipanel longitudinal mixed vector cluster analysis. Most in the audience will be more interested in the primary findings than the statistical minutia, and if they do come up with a question it's probably either (a) relatively easy, or (b) something you'd never have anticipated in a million years anyway. Have references for any unusual or exceedingly complex analyses and briefly summarize the key points. Also, it's not the end of the world to tell an audience member that you're not sure about something.

'My methodology could not be more fascinating. Plus I spent 3 years with it so how could it be uninteresting to anyone?'
Fifteen minutes is not enough time to describe your entire methodology. If you try to do so, you will lose a significant portion of the audience and you will find that you are ready to present your results just as the moderator holds up the 1-minute sign.

- Unless you are presenting a study about methodology or you have done something that represents a methodological breakthrough (possible but unlikely), you should cover your methods briefly, note significant limitations and get to the point of your presentation, which will usually be your results. Too often, presenters rush through their results because they have lingered lovingly over their methods. Too often in such cases, the audience is left asking, "What did they find?"

- You may be part of a panel presenting multiple facets of one study. If the prior speaker has presented the methodology in enough detail, do not repeat it when your turn comes. It tends to irritate an audience when a speaker says "my colleague just presented the methodology for our study, so I won't repeat it here. Now, our methods consisted of the following..."

- What these points highlight is the need to triage your study. You can't present everything, so make choices about what points are most important for the audience. At AP-LS, you probably don't need to explain what the Dusky criteria are for competence to stand trial, but when you give the same presentation in your first job talk, you may. Think about the level of depth that is appropriate, and how much weight to give background, methods, results, and discussion since you will never have enough time to go through everything.

\section{The Big Day:}

'If people usually think I'm entertaining after 2 cups of coffee, imagine how interesting I'll be after 6!'

- Adhering to your normal routine (as much as possible) on the day of your talk is generally a good idea. Anything that is markedly different (e.g., new suit, staying up all night, new shampoo) typically has little upside and can lead to unexpected outcomes (e.g., poorly fitting suit, oversleeping, allergic reaction to your shampoo). In particular, consume your normal allotment of stimulants and/or depressants prior to the presentation, whatever that 'normal' allotment happens to be. Being animated is great, but vibrating through the floor after your fourth mochachino (if you usually only have one) accomplishes little-and may be either funny or painful for the audience to watch, depending on how you handle your caffeine.

- Additionally, make sure that all your clothes are where they should be before you go to your session. Nothing shouts "Look at me mom - I dressed myself!” like bad static cling or a pant leg stuffed into a sock.

'It looked perfect on my computer. I'm sure it will look fine when I run it through the LCD projector for the first time in front of 50 people.'

- If at all possible, check out the room in which you are presenting and the equipment you're using, particularly to see if your Power Point presentation looks remotely like it looks on your computer. You may find that you cannot actually read the slides very well. The slides may be too crowded; the font may be too small (but not if you followed the suggestions above). Or in an attempt to convey your rich aesthetic sense you have chosen a color for your words that cannot be read against the color you have chosen for your background. It is wonderful to have good taste in matching colors. It is even better for the audience to be able to read your slides. Dark backgrounds with colored lettering sometime turns into 'dark on darker' when projected on a screen. As a safe choice, white

AP-LS presentation cont. on $p .10$ 
AP-LS Presentation con't from p. 9

backgrounds with black or dark blue lettering or white lettering on a (very) dark background are hard to screw up. Common mistakes are the use of light-colors for text, like light blue, orange, and pink. These look great on your computer, where you have a backlit display, but appear very dark when projected through and LCD projector in a dim, but not pitch black room.

- Related to the above point, another good reason to do the "room check" of your presentation is that the format you have on your monitor is not always a perfect match with the projector and computer you will be using. Do not assume that just because your slide show works on your home computer (or any other computer for that matter) that it automatically will magically appear correctly on-screen through an LCD projector on your supervisor's laptop bought back when Reagan was still president. Margins and tabs will often shift when you change computers, and can leave your tables misaligned and your text running off the page. Always check these things first, and it's still a good idea to have overhead transparencies with you as a back-up.

\section{The Talk Itself:}

'I'm the $4^{\text {th }}$ of 4 presenters. Time to meditate on the meaning of life until it's my turn.'

- It is very worthwhile for you to pay attention to what people speaking before you have said. There's no need to plug through things that someone just spent 5 minutes on a few minutes ago. This is particularly indefensible for a symposium, where people should have some sense of what the other presenters had planned to say. If you are presenting in a symposium, make sure you know what other presenters will be covering so you can minimize redundancy and make the most of your allotted time.

- Monitor the time as the session progresses and have a clear idea in advance of what you can most rea$(4)$ sonably skip over if the previous presenters took their share of the time and more or if you are running long. Particularly if you are running short of time, what's the take-home message for your audience? Don't let that get lost in reviewing the alpha levels for the dependent measures in your ancillary hypotheses. Limitations of your research, future directions, etc., usually are self-evident and can be easily jettisoned in most instances.

- On the same note, do not be greedy with your time: Use only what's yours and heed the time warnings of the moderator.

'I'm part of a symposium with someone I cited 470 times in my dissertation (and she just happened to do the world's most entertaining talk ahead of me). I may have to pass out now.'

- Everyone begins his or her career as an unknown. In addition, most of the people who will be listening to your talk, even the well-known ones, are very nice people who are quite used to watching graduate students and young professionals cut their teeth at conferences. All they expect is that you give it your best shot. So, although it is normal to have some anxiety when presenting with someone well known on the panel or in the audience, remember they were probably in a situation just like yours at some point in their career. Perhaps even think of it as an opportunity to make a positive impression.

'Time to do my thing. I'm determined to make sure that the next $15 \mathrm{~min}$ utes are not my first and only $15 \mathrm{~min}$ utes of fame...or infamy...'

For the talk itself, there are many common presentation mistakes that should be avoided. As we noted above, many of these can be curtailed by spending adequate time rehearsing.

- Do not read your slides during your presentation. The audience is literate and can read them more quickly to themselves than you can out loud.
It is also deathly boring to listen to an individual read his or her slides. A typical audience response to being bored is to simply quit listening. Besides, if you're following the rules about how much text, what font size, and how many slides you can get through, you can't write it all out. Slides should be considered notes, reminders, and a means of highlighting the points you want to make not a repetition of the entire talk. That's the purpose of journal articles.

- Do not try to convince yourself you aren't nervous if you are. Everyone expects you to be at least a little anxious. It's not a crime and, if anything, most people will be sympathetic.

- Do not spend the entire time looking at the screen and away from the audience. Not looking at them won't make them go away. Make eye contact with people in the audience, as much as possible and at least once.

- Move at least once from the obligatory stationary position most people assume at the podium. Nothing keeps people awake like a little motion.

- Although APLS is not open mike night at the Comedy Improv, try to be at least a little funny in some way, especially if it can be self-deprecating. However, do not try and tell a joke if you are not good at doing so.

- Do not be afraid of the 'pregnant pause.' If you get confused, take a drink of water and collect yourself. You do not need a perpetual stream of verbiage, which often seems prompted by anxiety and the 40 slides left for the remaining 2 minutes.

- Finally, having a friendly face in the audience you can focus on can be extremely comforting. Presentations in front of complete strangers are much more stressful than those where you have some perceived social support. This of course presumes your friend isn't the sort to make fun of you later.

'Where the !\#\$\%\&\$\%\#! is everyone? Don't they know how much work I put into this?' 
- You may encounter a related problem, when you find yourself presenting to a few classmates or friends while the room next to yours is packed with people wanting to hear the latest on a particular issue or from a particular speaker. This can be deflating. However, everyone goes through this at some point or another in his or her career. It should not cause you to let down and give a less enthusiastic talk than you otherwise would give. First, you owe it to yourself and those who took the time to come listen to you to do your best. Second, you never know even in a small audience who you might impress. Third, your classmates who came to support you are more likely to mean it when they tell you that you were great.

\section{The Fallout}

'Oh God, I can never show my face again in public'

- After finishing your first presentation ever, you may have a variety of reactions. A common one is that many people tend to beat themselves up somewhat, focusing more on what they did wrong than what they did well. Unless you're fairly narcissistic, you probably did better than you think. And don't devalue positive comments from those who watched your talk, particularly from strangers.

'They liked me, they really really liked me...'

- It is very flattering when people ask for your slides or paper. If you promise to send it to them, make sure that you do. The individual may have forgotten that she requested your pa- per five minutes after your presentation. On the other hand, the next time she meets you she may remember something about you-you once promised to send her something but did not.

In conclusion, to the best of our knowledge no one has ever died giving his or her first AP-LS presentation, and a bad presentation has never ruined anyone's career. The good news is that it seems to get progressively easier and, at least for some people, can even become an enjoyable experience. We hope these recommendations can alleviate some of the initial anxiety that is common with any public speaking scenario such as an AP-LS presentation. Having committed several of these mistakes ourselves, we hope others can benefit somewhat from these suggestions.

\section{EXECUTIVE COMMITTEE AND COMMITTEE CHAIRS}

- President

- Past-President

- President-Elect

- Secretary

- Treasurer

- Member-at-Large

- Member-at-Large

- Member-at-Large

- Council Representative

- Council Representative

- Newsletter Editor

- Publications Editor

- Law \& Human Behavior Editor

- Webpage Editor

- AP-LS/APA Liaison

- Careers and Training Committee

- Dissertation Awards

- Educational Outreach Committee

- Fellows Committee

- Grants-in-Aid

- Committee on Law and Psychology in Corrections

- Committee on Relations with Other Organizations

- Mentorship Committee

- Scientific Review Paper Committee

- Women in Law Committee

- Division Administrative Secretary

- 2005 APA Program Chairs

- 2006 APLS Conference Chairs
Edie Greene

Sol Fulero

Gary Wells

Jennifer Robbenalt

Margaret Bull Kovera

Christina Studebaker

Randall Salekin

Jen Skeem

Gail Goodman

Patty Griffin

Jen Groscup

Ron Roesch

Rich Wiener

Adam Fried

Marsha Liss

Allison Redlich

Eve Brank

Lavita Nadkarni

Kirk Heilbrun

Mario Scalora

Melissa Warren

Michele Galietta

Wendy Heath

Rich Wiener

Beth Schwartz

TBA

Jen Hunt

Eric Elbogen

Jennifer Groscup

Tonia Nicholls

Annette Christy egreene@uccs.edu

sfulero@sinclair.edu

gwells@iastate.edu

robbenaltj@missouri.edu

koveram@fiu.edu

cstudebaker@csopp.edu

rsalekin@bama.au.edu

jskeem@uic.edu

ggoodman@ucdavis.edu

pgriffin@navpoint.com

jgroscup@jjay.cuny.edu

rroesch@sfu.ca

wiener_richard@unl.edu

afried@fordham.edu

lissmb@state.gov

aredlich@prainc.com

ebrank@ufl.edu

lnadkarn@du.edu

kirk.heilbrun@drexel.edu

mscalora@unl.edu

mgw.apa@email.apa.org

galietta13@aol.com

heath@rider.edu

wiener_richard@baruch.cuny.edu

bschwartz@rmwc.edu

TBA

jhunt2@unl.edu

eric.elbogen@duke.edu

jgroscup@jjay.cuny.edu

tnichola@sfu.edu

achristy@fmhi.usf.edu 